\title{
Use of a soft silicone tube guide for an automatic suture device in video-assisted lung lobectomy
}

Norimasa Ito, MD, Takako Suda, MD, Tomoko Inoue, MD, Sakiko Yasui, MD, Yoshimasa Suzuki, MD, Yuji Taniguchi, MD, Kiyosuke Ishiguro, MD, and Shigetsugu Ohgi, MD, Tottori, Japan

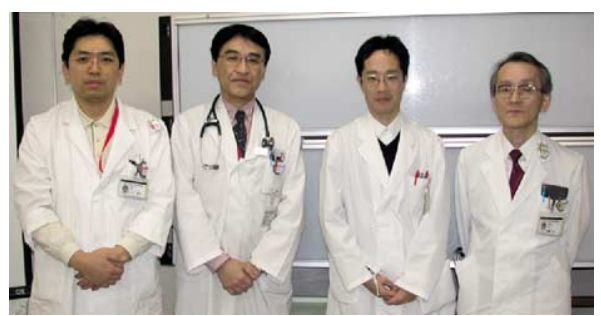

Taniguchi, Nakamura, Ito, Ohgi (left to right)

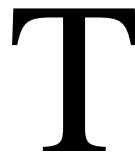

he frequency of using mechanical stapling for bronchus and vessels has increased for anatomic lung resection since video-assisted thoracoscopic surgery was introduced. ${ }^{1}$ However, when we staple vessels, bronchi, and lobes with an automatic suture device, the passage of the endostapler (Endo-GIA Universal, Tyco Healthcare) through them is occasionally hampered. A Penrose drain ${ }^{2}$ has been used to guide the tip of the endostapler. However, there are still some problems. At first, the Penrose drain is so soft that we cannot sometimes guide the endostapler. Accidental injuries of vessels with the tip of the endostapler can occur after removing the Penrose drain. We introduce a new instrument made with a soft silicone tube to guide an endostapler more safely and quickly.

\section{Materials}

The guide is made with a smooth-surfaced soft silicone tube $5 \mathrm{~mm}$ in internal diameter, $0.75 \mathrm{~mm}$ thick, and $60 \mathrm{~cm}$ long (Ethicon). Both ends of the tube are shaped obliquely (Figure 1).

\section{Methods}

We used the silicone tube guide on 29 firings (24 vascular and 5 bronchial sutures) in 7 patients undergoing video-assisted lung lobectomy. We used a Penrose drain on 18 firings (14 vascular and 4 bronchial sutures) in 4 patients who were control subjects.

First, we dissect and tape the blood vessels, bronchus, and interlober space carefully with tweezers. The silicone tube or Penrose drain is passed behind the vessel, bronchus, or lung tissue with tweezers. An end of the guide is led out of the body. One end of the tube is squeezed onto the jaw tip of the endostapler. By using the guide, the jaw of the endostapler is guided behind the

From Organ Regeneration Surgery, Faculty of Medicine, Tottori University, Tottori, Japan.

Received for publication Dec 26, 2004; accepted for publication Jan 18, 2005 .

Address for reprints: Norimasa Ito, MD, Organ Regeneration Surgery, Faculty of Medicine, Tottori University, 36-1 Nishimachi, Yonago, Tottori, 683-8504, Japan (E-mail: noitou@ @otmail.co.jp).

J Thorac Cardiovasc Surg 2005;130:931-2

$0022-5223 / \$ 30.00$

Copyright $\odot 2005$ by The American Association for Thoracic Surgery doi:10.1016/j.jtcvs.2005.01.023

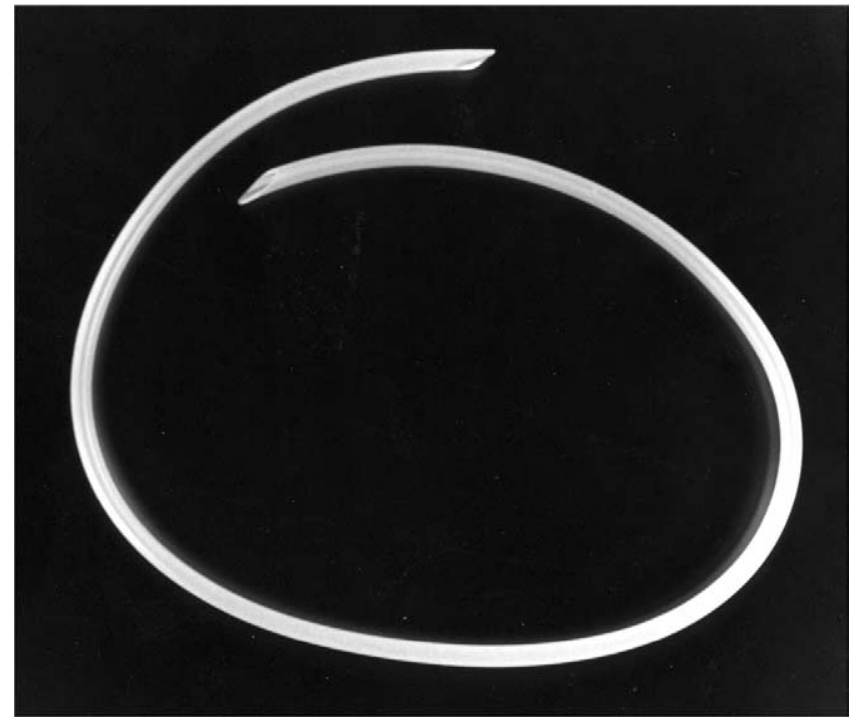

Figure 1. The silicone tube guide has an internal diameter of $5 \mathrm{~mm}$, a wall thickness of $0.75 \mathrm{~mm}$, and a length of $70 \mathrm{~cm}$. The tips are shaped obliquely to attach the tip of the endostapler.

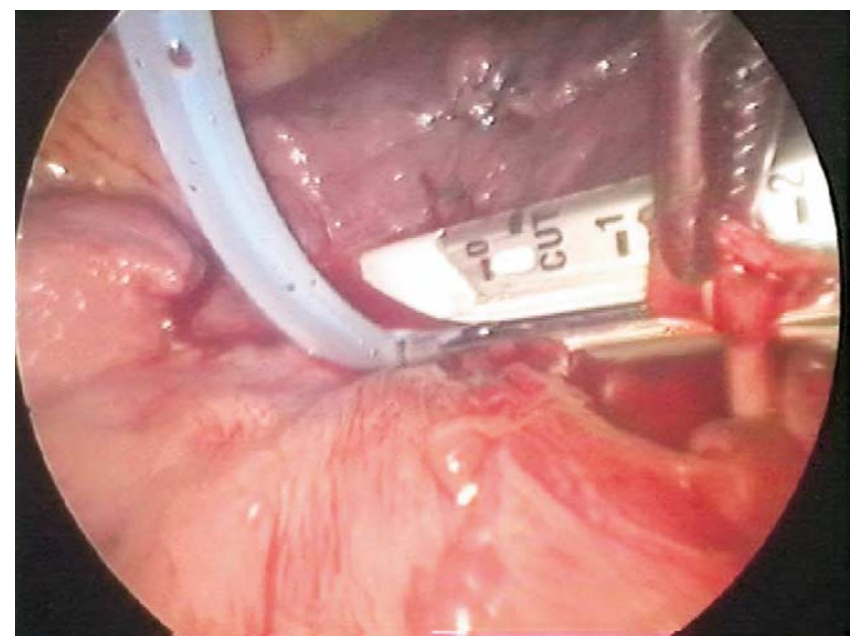

Figure 2. Use of an automatic suture device with the guide attached. 
vessel, bronchus, or interlobar space. When a silicone tube guide is used, the vessel, bronchus, or lung tissue is stapled while keeping the guide attached (Figure 2). When the Penrose drain is used, we remove the drain from the tip of the endostapler and then staple the tissue.

\section{Results}

There was no misfire or accidental injury of vessels or surrounding tissues in the use of the endostapler. The time between dissecting the vessels and the end of stapling with the silicone tube guide was significantly shorter than that with the Penrose drain (mean $\pm \mathrm{SE}$ : silicone tube, $191 \pm 25$ seconds; Penrose drain, $392 \pm 94$ seconds; $P<.01)$.

\section{Discussion}

Mechanical stapling for vessels and bronchus is a safe method, especially in video-assisted thoracoscopic lung lobectomy. A Penrose drain has been used as a guide for the endostapler. However, it must be detached from the jaw of the endostapler before stapling near the hilum of the lung in the thoracic cavity. The elasticity of the Penrose drain is so soft that it occasionally fails to lead the endostapler behind the vessel.
The silicone tube guide is so small that we can pass the $11-\mathrm{mm}$ port as it is attached to the jaw, and therefore the attachment on the jaw can be made out of the body. In addition, an endostapler can be attached to either side of the silicone guide. It has elasticity appropriate for guiding the tip of the endostapler. The biggest advantage of this guide is that stapling can be done with the guide attached. We can control the position of the tip of the endostapler at the time of stapling with the silicone tube. It simplifies intrathoracic manipulation and eliminates the possibility of injuring other vessels or lung tissue with the jaw. It also saves operating time.

\section{Conclusions}

The use of a soft silicone tube guide can improve the safety of lung lobectomy with automatic suture devices and shorten the operative time.

\section{References}

1. Szwerc MF, Landreneau RJ, Santos RS, Keenan RJ, Murray GF. Minithoracotomy combined with mechanically stapled bronchial and vascular ligation for anatomical lung resection. Ann Thorac Surg. 2004; 77:1904-9.

2. Abramson DJ. Charles Bingham Penrose and the Penrose drain. Surg Gynecol Obstet. 1976;143:285-6.

\section{Mitral valve reconstruction in a compound heterozygote for sickle cell anemia and hemoglobin Lepore}

Konstantinos Tziomalos, MD, ${ }^{a}$ Vassilia Garipidou, MD, ${ }^{\text {a }}$ Eleni Houmpouridou, MD, ${ }^{\mathrm{b}}$ Antonios A. Pitsis, MD, ${ }^{c}$ and Elias Basayannis, MD, ${ }^{a}$ Thessaloniki, Greece

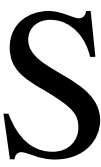

ickle cell disease presents a multitude of challenges in patients undergoing cardiac operations. In these patients, cardiopulmonary bypass (CPB) may trigger a crisis of profound magnitude. The prevention of sickling of red blood cells and its sequelae of hemolysis and

\footnotetext{
From the Second Propaedeutic Department of Internal Medicine, Aristotle University of Thessaloniki, Hippokration Hospital, ${ }^{\mathrm{a}}$ and the Department of Hematology ${ }^{\mathrm{b}}$ and the Thessaloniki Heart Institute, ${ }^{\mathrm{c}}$ St Luke's Hospital, Thessaloniki, Greece,

Received for publication Jan 23, 2005; accepted for publication Feb 22, 2005.

Address for reprints: Konstantinos Tziomalos, MD, 63 Solonos St, Thessaloniki, 54248 Greece (E-mail: ktziomalos@yahoo.com).

J Thorac Cardiovasc Surg 2005;130:932-3

$0022-5223 / \$ 30.00$

Copyright $\odot 2005$ by The American Association for Thoracic Surgery

doi:10.1016/j.jtcvs.2005.02.037
}

vaso-occlusive crises during $\mathrm{CPB}$ is achieved primarily by reducing the level of

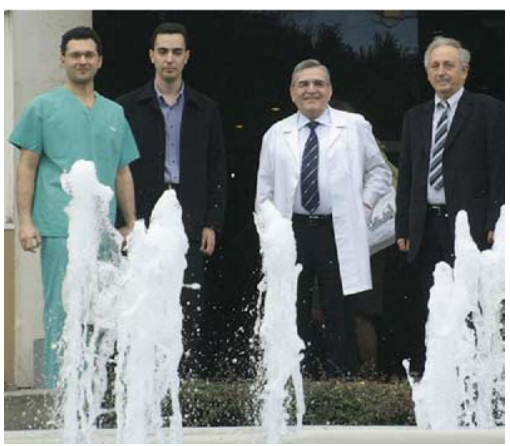

Pitsis, Tziomalos, Katsarkas, Basayannis (left to right) hemoglobin $\mathrm{S}$ before operation. $^{1,2}$

Hemoglobin Lepore $(\alpha 2[\delta \beta] 2)$ is a hemoglobin variant with a $\delta \beta$ chain that is a result of fusion of a $\delta$ and a $\beta$ globin gene. The hybrid gene is expressed at a roughly intermediate level, between the $\delta$ and the $\beta$ globin genes. The phenotype of the heterozygote thus closely resembles the classical thalassemia trait. To date, only 20 cases of compound heterozygotes with hemoglobin Lepore/hemoglobin S have been reported, and they are characterized by hematologic as well as clinical heterogeneity. The hemoglobin S/hemoglobin Lepore combination may have enough hemoglobin $\mathrm{S}$ to cause serious sickling, particularly if an excess of $\delta$ chains were to have harmful consequences, as has been asserted. ${ }^{3}$ We report a case of mitral valve reconstruction performed safely in a compound heterozygote for sickle cell anemia and hemoglobin Lepore. 